
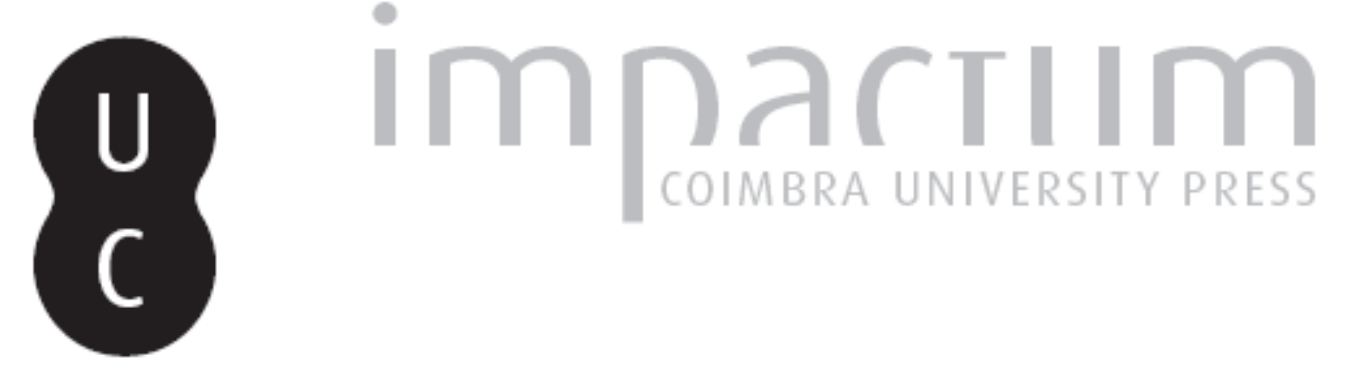

\title{
Morte do rei, incorporação do poder e representação histórica: entre uma poética da ausência e uma poética do saber?
}

\author{
Autor(es): $\quad$ Marcelino, Douglas Attila
}

Publicado por: Imprensa da Universidade de Coimbra

URL persistente:

URI:http://hdl.handle.net/10316.2/40211

DOI:

DOI:https://doi.org/10.14195/2183-8925_34_5

Accessed : $\quad$ 26-Apr-2023 09:05:23

A navegação consulta e descarregamento dos títulos inseridos nas Bibliotecas Digitais UC Digitalis, UC Pombalina e UC Impactum, pressupõem a aceitação plena e sem reservas dos Termos e Condições de Uso destas Bibliotecas Digitais, disponíveis em https://digitalis.uc.pt/pt-pt/termos.

Conforme exposto nos referidos Termos e Condições de Uso, o descarregamento de títulos de acesso restrito requer uma licença válida de autorização devendo o utilizador aceder ao(s) documento(s) a partir de um endereço de IP da instituição detentora da supramencionada licença.

Ao utilizador é apenas permitido o descarregamento para uso pessoal, pelo que o emprego do(s) título(s) descarregado(s) para outro fim, designadamente comercial, carece de autorização do respetivo autor ou editor da obra.

Na medida em que todas as obras da UC Digitalis se encontram protegidas pelo Código do Direito de Autor e Direitos Conexos e demais legislação aplicável, toda a cópia, parcial ou total, deste documento, nos casos em que é legalmente admitida, deverá conter ou fazer-se acompanhar por este aviso.

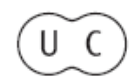



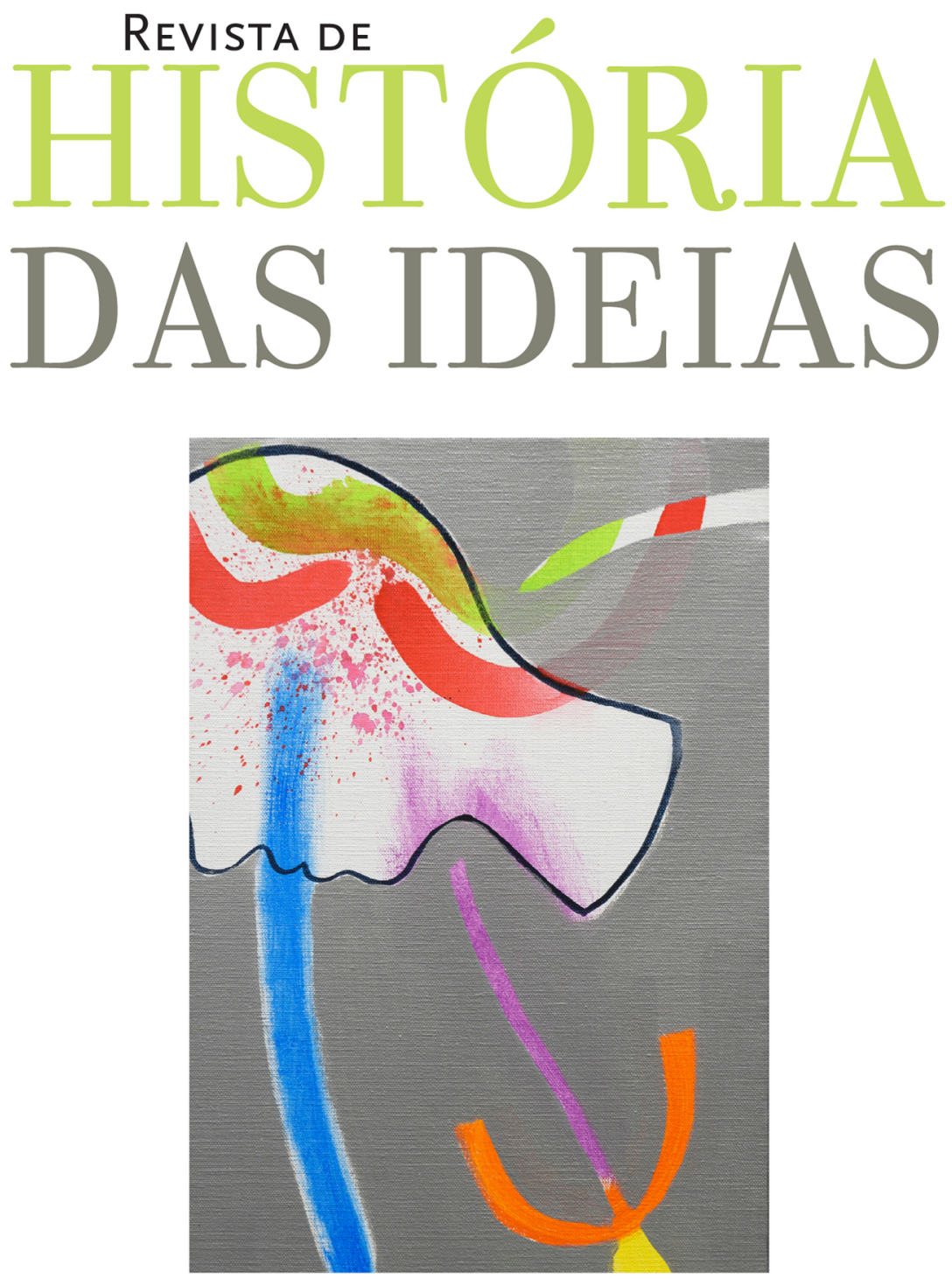

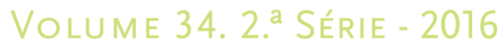




\title{
MORTE DO REI, INCORPORAÇÃO DO PODER E REPRESENTAÇÃO HISTÓRICA: ENTRE UMA POÉTICA DA AUSÊNCIA E UMA POÉTICA DO SABER? \\ DEATH OF THE KING, INCORPORATION OF POWER AND \\ HISTORICAL REPRESENTATION: BETWEEN A POETICS OF ABSENCE AND A POETICS OF KNOWLEDGE?
}

\author{
Douglas Attila MarcelinO* \\ douglasattila@gmail.com \\ Universidade Federal de Minas Gerais, Brasil \\ Texto recebido em / Text submitted on: 23/05/2016 \\ Texto aprovado em / Text approved on: 28/07/2016
}

\section{Resumo:}

Este artigo analisa estudos sobre temas como os da morte do rei, das formas de incorporação do poder e dos modos de representação histórica. Eles servem de ponto de partida para uma reflexão sobre a historiografia como forma de discurso caracterizada por certa configuração poética e por seus fundamentos como rito de recordação. O primeiro aspecto a relaciona a um imaginário político e o segundo a práticas por meio das quais os homens conferem sentido às demandas pelo pertencimento a corpos coletivos imaginários. Apesar do diálogo estabelecido

* As ideias apresentadas neste artigo são parte de um estudo mais amplo sobre a história da historiografia da morte. A pesquisa se beneficiou do auxílio financeiro do CNPq e do Programa Santander Universidades - Bolsas Ibero-Americanas para Jovens Professores e Pesquisadores, por meio do qual permaneci dois meses (entre janeiro e março de 2016) como investigador estrangeiro na Universidade de Coimbra. 
com autores diversos, como Louis Marin, Claude Lefort e Mona Ozouf, tornamse centrais as interrogações de Jacques Rancière sobre uma «poética do saber»e de Fernando Catroga sobre uma «poética da ausência».

\title{
Palavras-chave:
}

Historiografia, imaginário político, representação histórica, poética do saber, poética da ausência.

\begin{abstract}
:
The present article analyzes studies about themes such as the death of the king, the ways for incorporating power and the forms of historical representation. These serve as a starting point for a reflection about historiography as a form of discourse characterized by certain poetic configuration and by its fundaments as rite of remembrance. The first aspect relates it to political imagination and the second one to practices through which man attributes sense to demands by belonging to imaginary collective bodies. Despite the dialogue established with diverse authors, such as Louis Marin, Claude Lefort and Mona Ozouf, the interrogations by Jacques Rancière about a "poetics of knowledge» and by Fernando Catroga about a «poetics of absence» become central.
\end{abstract}

\section{Keywords:}

Historiography, political imagination, historical representation, poetics of knowledge, poetics of absence.

Poucos estudos foram tão profundos no tratamento dos modos de incorporação do poder característicos de um imaginário político, suas vinculações com os rituais que dramatizavam a presença do corpo real na França do absolutismo e com as formas da representação histórica quanto o de Louis Marin ${ }^{(1)}$. Seu investimento analítico nos dispositivos narrativos por meio dos quais o Projet de l'histoire de Louis XIV, endereçado a Colbert por Pellison-Fontanier, fazia não apenas o elogio do rei, mas repercutia as estruturas imaginárias de um poder que se desejava absoluto, tratava da relação entre corpo e política por meio de uma análise das formas de teatralização do poder e suas vinculações com as especificidades da escrita da história como gênero de discurso marcado pelo valor então conferido ao estudo da retórica.

Elaborado visando obter a subvenção real, o texto de Pellison descrevia diretamente as estratégias retóricas que deveriam ser utilizadas

(1) Louis Marin, Le portrait du roi, Paris, Minuit, 1981. 
para louvar o rei sem que o discurso narrativo se evidenciasse como um discurso de louvor, reenviando para os três gêneros de discurso público definidos por Aristóteles na Retórica, embora enfatizasse sua diferença em relação às formas do elogio e do panegírico ${ }^{(2)}$. Marin exploraria à exaustão todas as filigranas que compunham o dispositivo discursivo por meio do qual Pellison regularia, em «golpes sucessivos», a «composição progressiva» dos «efeitos de força» da estratégia narrativa colocada em jogo, visando obter um «efeito de louvor» que não poderia ser alcançado senão de forma dissimulada. Fazer o leitor comparar sem saber que o estava fazendo e compor a narrativa à forma de uma pintura, em que cada palavra é devidamente escolhida para formar um quadro e pôr diante dos olhos do público as ações relatadas, eram alguns dos dispositivos retóricos que fundamentavam um modo de representação histórica que, tal como uma encenação teatral, montada peça por peça, simulava a própria presença real. Tratava-se de um dispositivo pelo qual «contar é pintar, narrar é fazer ver à imaginação do expectador porque este momento da história é o presente fulgurante e permanente onde a substância real faz ver suas perfeições» ${ }^{(3)}$.

Nessa perspectiva, as formas da enunciação analisadas por Emile Benveniste deveriam ser compreendidas em sua realização histórica, além de tornarem-se um problema não apenas teórico, mas político, tendo em vista a relação entre o modo de construção de uma narrativa em que não existem sujeitos da história contada e a pressuposição de que havia um «único sujeito universal», um «único ator absoluto da história», ou seja, o próprio rei. Implicações semelhantes poderiam ser percebidas no modo de construção da temporalidade que caracterizava o discurso, já que a crítica ao mero registro e à crônica ficava também submetida ao imaginário do poder absoluto, com seu estabelecimento de uma lógica de causalidade ou sua busca das forças da história nas ações do monarca, «pois o sujeito absoluto da História é necessariamente por sua ação mesma o princípio produtor da temporalidade histórica» ${ }^{(4)}$. Numa concepção pela qual a história não seria feita por uma pluralidade de sujeitos independentes uns dos outros ou interagindo entre si, mas por um único sujeito universal,

(2) Louis Marin, Le portrait..., cit., p. 49-115. Todas as traduções neste artigo são livres.

(3) Louis Marin, Le portrait..., cit., p. 106.

(4) Louis Marin, Le portrait..., cit., p. 59. 
torna-se «evidente que o fator de unificação temporal das ações e dos eventos não pode ser outro que a temporalidade desse sujeito» ${ }^{(5)}$.

O mais importante é que, por trás das intenções do discurso político, com suas estratégias de deslocamento em relação aos modos retóricos do elogio e do panegírico, estava um imaginário do poder no qual essas racionalizações que calculavam a distribuição e a composição progressiva dos efeitos de força que a escrita deveria mobilizar estavam enraizadas. Ou seja, a própria racionalização política se fundamentava num desejo, num imaginário do absolutismo:

O que nos interrogamos aqui é sobre uma operação mais complexa e de outra natureza: como se pensa um poder que se deseja absoluto? Qual é a fantasmática na e pela qual se racionaliza a política deste desejo? Qual é o imaginário do absolutismo, e o papel e a função do historiógrafo na constituição desta fantasmática e na construção deste imaginário? ${ }^{(6)}$.

As próprias racionalizações em torno dos dispositivos retóricos que deveriam compor o simulacro da presença real estavam submetidas ao imaginário de «um poder que se pensa absoluto», remetendo para as formas específicas de incorporação do poder que caracterizavam uma teologia política centrada na dupla natureza do corpo do monarca. A reflexão de Marin sobre o projeto historiográfico de Pellison estava, portanto, vinculada a interrogações sobre o modo de funcionamento do dispositivo da representação, compreendida esta última como substituição do ausente e como efeito de presença, tendo em vista a relação estabelecida entre o modelo eucarístico que fundamentou a teoria do signo dos lógicos e gramáticos de Port-Royal e o imaginário em torno do monarca absolutista. Tal como a representação pictórica (o retrato do rei), a elaboração historiográfica remetia simultaneamente para a «representação de um corpo histórico ausente, a ficção de um corpo simbólico (o reino no lugar da Igreja) e a presença real de um corpo sacramental, visível sob tantas espécies que o dissimulam» ${ }^{(7)}$.

Num plano mais profundo, Marin produzia uma reflexão não apenas sobre as formas de representação do poder relacionadas ao imaginário do absolutismo e suas vinculações com um projeto de escrita

(5) Louis Marin, Le portrait..., cit., p. 49.

(6) Louis Marin, Le portrait..., cit., p. 59.

(7) Roger Chartier, À beira da falésia, Porto Alegre, UFRGS, 2002, p. 167. 
da história, mas se interrogava sobre o modo como sua própria análise dos discursos (historiográfico e pictórico) era também uma forma de representação, tendo em vista as relações entre força, justiça e efeitos de sentido estabelecidas por meio do diálogo com o pensamento de Pascal. Ao indicar que, fundamentando a justiça, havia sempre a força que instituía um imaginário por meio dos discursos e seus efeitos de sentido, Pascal produziu um pensamento crítico da representação que, operando pela construção-desconstrução como forma de produção de sentido, apostou no caráter contraditório de todo discurso de verdade, já que o saber humano sobre Deus ou sobre si mesmo seria marcado por oposições irredutíveis ${ }^{(8)}$. Seu discurso não se constituía como um metadiscurso ou como um modelo teórico centrado nos princípios da representação, aproximando-se mais de uma prática de escrita cujas operações de produção de sentido funcionavam como «condição negativa de possibilidade da verdade do discurso em geral» ${ }^{(9)}$.

Na leitura de Marin, se o discurso de Pascal não anulava a força como fundamento da construção de sentido, tendia a neutralizá-la por meio da forma com que se apresentava: fragmentária, dispersiva, na qual, constantemente, a «força recebe uma direção contrária àquela que ela tinha na produção de seu efeito» ${ }^{(10)}$. Inviabilizando qualquer «síntese dialética» ou «totalização progressiva» do saber, a escrita pascaliana operava por um deslocamento interminável, não se fixando numa posição e configurando um entre-deux como lugar de indeterminação do sujeito da enunciação:

A posição fixa, de um lado, e o pensamento ao infinito do infinito, de outro, marcam a dissolução de todo lugar da verdade, teórico ou prático. Trata-se, de uma só vez, do lugar do evento do sentido na consciência e da impossibilidade de dizer este sentido como tal num discurso que seria aquele do sentido. O sentido se retira infinitamente de seu discurso ${ }^{(11)}$.

Essa fragmentação da força como origem do sentido, para Marin, guardaria relação com a própria forma com que o pensamento pascaliano

(8) Louis Marin, Le portrait..., cit., p. 23-46; La critique du discours: sur la «Logique de PortRoyal» et les «Pensées» de Pascal, Paris, Minuit, 1975. Blaise Pascal, Pensées, Paris, Gallimard, 1962. Blaise Pascal, Pensamentos sobre a política, São Paulo, M. Fontes, 1994.

(9) Louis Marin, La critique..., cit., p. 400.

(10) Louis Marin, La critique..., cit., p. 372.

(11) Louis Marin, Le portrait..., cit., p. 32. 
era apresentado, por meio do caráter dispersivo de suas parábolas, conformando uma «ausência significante» na qual o lugar da verdade era inalcançável ao homem e as oposições permaneciam insolúveis ${ }^{(12)}$. Embora não rompesse totalmente com o discurso ordinário, compreendido como a origem de todos os discursos, a escrita de Pascal caracterizava-se por uma «ironia infinita» e desconfiava das certezas daquele e de outros discursos. Suas formulações, que apontavam para reflexões teológicas mais profundas sobre a condição humana ${ }^{(13)}$, seriam retomadas de forma crítica por Marin em suas análises das representações pictóricas e do projeto historiográfico de glorificação do rei na monarquia absolutista.

Talvez seja nesse sentido que possamos compreender o fato de Paul Ricoeur, ao tratar do livro de Marin, colocar suas reflexões sobre a categoria «grandeza» nos planos do antropológico e do político, o que permitiria pensar a perenidade do poder e, portanto, a possível persistência de uma retórica do louvor na própria historiografia da época democrática:

A questão, para nós, será saber se, com o fim da monarquia de Antigo Regime e a transferência para o povo da soberania e de seus atributos, a historiografia pode eliminar da representação todo traço do discurso de louvor. Será perguntar, ao mesmo tempo, se a categoria grandeza e aquela que lhe é conexa, de glória, podem desaparecer sem deixar traço do horizonte da história do poder. [...] A democracia moderna pôs fim ao elogio do rei e à fantasmática colocada a serviço deste elogio ${ }^{(14)}$.

De fato, a categoria «grandeza», no pensamento pascaliano, remetia não apenas para as três «ordens de grandeza», que incluíam a política ${ }^{(15)}$, mas para uma leitura da natureza do homem e sua relação com o plano divino, fundamentando uma espécie de «ontologia da diferença cujas manifestações são os teologemas da Eucaristia e do Deus escondido» ${ }^{(16)}$.

(12) Louis Marin, La critique..., cit., p. 375.

(13) Os limites do saber indicados guardam relação com a percepção de Pascal sobre a natureza do homem, caracterizado pela grandeza, de origem divina, e pela miséria, proveniente do pecado original. Franklin Leopoldo e Silva, "Introdução" in Blaise Pascal, Pensamentos, São Paulo, M. Fontes, 2000, p. VIII.

(14) Paul Ricoeur, La mémoire, l'histoire, l'oubli, Paris, Seuil, 2000, p. 348.

(15) A política estava referida à ordem da carne, havendo ainda as ordens do espírito (da razão) e da caridade (do coração). Conferir o fragmento 111 (p. 65) e o Prefácio de André Comte-Sponville (p. 55 ss.) em Blaise Pascal, Pensamentos sobre..., cit.

(16) Louis Marin, La critique..., cit., p. 418. 
Partindo de outros pressupostos, Marin produziu uma leitura crítica que não deixou de colocar num plano utópico a pretensão de elaborar um discurso que produz sentido sem qualquer determinação de um lugar: o próprio pensamento de Pascal «está em um ponto, mesmo se este ponto se desloca ao infinito ou com uma velocidade infinita; ele está em um lugar, mesmo se este lugar é indeterminado e indeterminável [...]» ${ }^{(17)}$. Seria difícil duvidar de que, para Marin, aspectos de uma retórica do louvor permaneceriam nas formas de representação histórica da época democrática. Estando a força na base da produção do sentido, a justificação de qualquer discurso se fundamentaria em critérios que são estabelecidos de forma histórica e, portanto, arbitrária: as próprias leis de uma ordem determinada de grandeza, nos termos pascalianos. Trata-se, por outro lado, de se interrogar sobre a tensão produzida em relação aos critérios de grandeza por um discurso que buscaria justamente colocá-los em questão, assim como suas novas conformações na época democrática, tendo em vista possíveis alterações nas formas da representação histórica e suas relações com reconfigurações mais profundas nos modos de incorporação do poder e nas formas de experiência sensível.

\section{Morte do rei e poética da história na era democrática}

A mobilização intencional dos dispositivos retóricos indicada por Pellison visando obter a subvenção real para a realização de seu projeto historiográfico estava relacionada com um uso marcadamente regrado dos discursos, em que, à lógica de estabelecimento de grandes classificações hierárquicas dos gêneros literários e oratórios, correspondia uma concepção organicista da sociedade, caracterizada pela teologia política que fundamentava um modo determinado de incorporação do poder e, portanto, de vinculação entre o monarca e seus súditos. Um dos estudos que tentaram compreender como as transformações simbólicas nos modos de incorporação do poder características do fim do regime monárquico afetaram a própria representação histórica foi o ensaio de Jacques Rancière sobre uma "poética do saber» ${ }^{(18)}$.

(17) Louis Marin, La critique..., cit., p. 400.

(18) Jacques Rancière, Les noms de l'histoire. Essai de poétique du savoir, Paris, Seuil, 1992. 
As interrogações do autor sobre o estabelecimento de uma nova lógica do regime de representação, suas relações com a construção imaginária de comunidades políticas e com as transformações poéticas que reconfiguraram as formas de racionalidade histórica no pós-1800 podem ser aproximadas dos questionamentos de Louis Marin e Paul Ricoeur. O mesmo pode ser dito em relação às suas reflexões sobre uma «partilha do sensível» ${ }^{(19)}$, segundo as quais a estética, estando na própria base da política, remeteria para «um recorte dos tempos e dos espaços, do visível e do invisível, da palavra e do ruído que define ao mesmo tempo o lugar e o jogo da política como forma de experiência». Assim, «a política volta-se para o que se vê e o que se pode dizer, para quem tem a competência para ver e a qualidade para dizer, para as propriedades dos espaços e os possíveis do tempo» ${ }^{(20)}$. Foi esse pressuposto de uma indissociabilidade entre estética e política, inclusive, que permitiu colocar em questão as clássicas teses benjaminianas sobre uma estetização da política na era das massas ${ }^{(21)}$.

Em termos históricos, Rancière indicava toda uma reconfiguração do mapa da experiência sensível na época democrática, inexoravelmente relacionada às transformações na ordem simbólica que confere sentido ao poder e ao estabelecimento do que chamaria de «regime estético das artes» (22). Tratava-se, de fato, de uma verdadeira revolução nas estruturas poéticas que, manifestando-se primeiramente na literatura, rompia com uma lógica da representação fundada numa rígida hierarquia dos gêneros pela suposta dignidade dos temas, embora estivesse relacionada também com a maior autonomia conferida ao campo da arte. Subvertia-se, assim, um regime de experiência sensível intimamente vinculado a uma visão hierárquica da sociedade, em que a lógica da representação do poder remetia ao corpo do rei como incorporação da comunidade política, ou seja, com todo um imaginário político que, conforme analisado por Louis Marin, fundamentava formas determinadas de representação histórica.

Assim, partindo do pressuposto de que os modos de configuração poética de um sistema representativo remetem sempre para figuras de comunidades imaginadas, tendo em vista os fundamentos subjetivos

(19) Jacques Rancière, Le partage du sensible, Paris, La Fabrique-Éditions, 2000.

(20) Jacques Rancière, Le partage..., cit., p. 13-14.

(21) Jacques Rancière, Le partage..., cit., p. 13.

(22) Jacques Rancière, Le partage..., cit. 
da política, Rancière podia utilizar o problema da reformulação das formas de representação do poder advinda da crise de legitimidade pós-Revolução Francesa para colocar em evidência uma suposta transformação nas estruturas poéticas da representação histórica ${ }^{(23)}$. Michelet apareceria, então, como o autor inaugural desse novo regime de composição poética, subvertendo os modos de enunciação histórica ao introduzir o relato no sistema do discurso e conjugar em sua própria escrita formas discursivas vinculadas a sistemas diversos no livro clássico de Emile Benveniste ${ }^{(24)}$. Os novos usos dos tempos e formas pessoais do verbo estariam em conformidade com as desordens da arte e as arbitrariedades da época democrática, fundamentando um rompimento com os modelos rígidos de representação que se tornaria matriz das formas de representação histórica da «nova história» no século XX.

Apesar dessa enorme generalização acerca das estruturas poéticas da nova história, o estudo de Rancière visava indicar que os modos recéminaugurados de representação histórica expressavam os fundamentos simbólicos de uma nova ordem de representação do poder, pois os critérios de sentido que buscavam os significados mais profundos de acontecimentos como a Revolução Francesa figuravam entidades abstratas como o povo, a nação, ou mesmo a França como sujeitos que se originavam daquela experiência. Tratava-se, portanto, de uma reestruturação da experiência sensível como fundamento simbólico de uma ordem política, tendo em vista que a impossibilidade de incorporação do poder afetava tanto o indivíduo, em seu recém-inaugurado ser junto sem lugar nem corpo, quanto os atributos da soberania, dispersos no anonimato de entidades incorpóreas que substituíam o corpo do rei nesse novo contrato simbólico da época democrática.

Ao tentar preencher esse vazio do poder com uma nova estrutura poética de representação histórica, entretanto, Michelet não apenas dava visibilidade ao povo como novo sujeito do discurso histórico, mas selava o contrato simbólico que calava este mesmo povo, figurado numa entidade abstrata sem dissenso e sem palavra, pelo menos se a tomada da palavra for compreendida como lugar dos excessos que permitem pôr continuamente em causa o corpo político. Eliminando as palavras sem corpo e apaziguando o passado, Michelet representava o passo

(23) Jacques Rancière, Les noms..., cit.

(24) Emile Benveniste, Problèmes de linguistique générale, Paris, Gallimard, 1966. 
fundamental em direção ao contrato narrativo, político e científico da época democrática, pelo qual a historiografia tentava suprimir qualquer relação com a literatura e a política. A figuração das massas anônimas como sujeito da história não apenas permitia estabelecer uma continuidade entre a escrita histórica de Michelet e a «nova história», mas também tomá-la como sintoma de uma revolução das formas de experiência sensível que, como manifestação estético-política da época democrática, se expressou antes na literatura do que na história, numa atitude paradoxal pela qual visibilidade e emudecimento poderiam andar conjugados.

Foi justamente nesse sentido que o problema da morte ganhou espaço no texto de Rancière, funcionando como pretexto para a elaboração de metáforas que colocavam em jogo a necessidade de uma reestruturação poética da historiografia. Na verdade, todo o ensaio Les noms de l'histoire se organiza metaforicamente em torno da morte do rei, cuja discreta presença na obra máxima de Fernand Braudel figuraria não apenas seu descentramento como lugar de encarnação do poder e, portanto, de força explicativa da história, mas também seu correlato historiográfico como crônica de feitos dos grandes personagens (os «nomes» da história). À busca braudeliana por conferir uma morte republicana ao rei corresponderia o silenciamento da historiografia francesa acerca da violência do regicídio e, de um modo irônico, todo o dispositivo teórico rigoroso do qual os anseios necrófilos de Michelet seriam sintomas. Assim, além da metáfora mais evidente que relacionava a configuração de uma história do povo com a ocupação do lugar do morto (o rei como fundamento do corpo político), tratava-se de uma escrita histórica que, ela também, acabou por ocupar o lugar do morto que trazia como novo personagem de sua narrativa, silenciando o tumulto de vozes que caracterizava esse segundo morto: em última instância, a própria política como campo do dissenso.

Retirando à história a imprevisibilidade dos acontecimentos e preenchendo as lacunas e ausências do saber com uma escrita em que tudo fala e tudo tem sentido, Michelet ocupava o lugar dos sujeitos do passado e suas experiências, mortificados «por não saber e por não saber dizer o que viver quer dizer» ${ }^{(25)}$. Nenhum traço de incerteza, morte e inessencialidade como "aparências do passado» figuravam nessa narrativa de um autor cuja paixão pelo túmulo podia «reduzir-se à sobriedade do jogo lógico pelo qual as produções do ser falante são

(25) Jacques Rancière, Les noms..., cit., p. 127. 
curadas de toda ferida da ausência» ${ }^{(26)}$. Sem interrogar-se sobre suas próprias lacunas, Michelet estabelecia a certeza do saber que conferia novo significado ao contrato científico relativo à ordem democrática, pois «a inclusão da morte e a teoria do testemunho mudo são uma só e mesma teoria: uma teoria do lugar da fala» ${ }^{(27)}$. As referências a Michel de Certeau são evidentes, assim como a busca por critérios para uma recomposição poética da historiografia.

Na verdade, o anseio por uma reconfiguração poética da historiografia aparecia em tensão com a constatação histórica das bases de seu próprio estabelecimento. Isto porque o deslocamento em relação à história dos grandes personagens e seus feitos faria parte da mesma revolução estética que estabeleceu uma nova ficcionalidade, pela qual a soberania estética da literatura teria desconstruído as fronteiras entre «razões dos fatos» e «razões da ficção», dada a impossibilidade de separar modelos de inteligibilidade e causalidade dos próprios eventos ${ }^{(28)}$. Rompendo com os critérios da distinção aristotélica entre história e poesia, que separavam a lógica da necessidade ou da verosimilhança da simples narração do que aconteceu em sua singularidade, a época romântica teria intensificado a percepção de que o real tem que ser ficcionalizado para ser pensado, tornando mais evidente que os enunciados políticos e literários têm efeitos sobre o real. Atuando sobre os corpos coletivos imaginários, os enunciados, nessa perspectiva, desenham:

comunidades aleatórias que contribuem para a formação de coletivos de enunciação que recolocam em questão a distribuição dos papéis, dos territórios e das linguagens - em síntese, desses sujeitos políticos que colocam novamente em causa a partilha dada do sensível. Mas, precisamente um coletivo político não é um organismo ou um corpo comunitário. As vias da subjetivação política não são as da identificação imaginária, mas as da desincorporação «literária» ${ }^{(29)}$.

Essa finalidade atribuída por Rancière aos enunciados, como vias de fragilização dos corpos coletivos imaginários, parece sintonizada com as propostas implícitas de uma nova poética da historiografia adequada às

(26) Jacques Rancière, Les noms..., cit., p. 133.

(27) Jacques Rancière, Les noms..., cit., p. 133.

(28) Jacques Rancière, Le partage..., cit., p. 61 ss.

(29) Jacques Rancière, Le partage..., cit., p. 61 ss. 
demandas da experiência democrática. A retomada da democracia como tema em La haine de la démocratie, em que seria pensada não como forma de governo, mas relacionada a novos modos de subjetivação política, parece sintomática. Significando a própria impureza na política, a democracia conformaria um jogo perpétuo de invenção de formas de subjetivação que contrariariam as tendências sempre existentes de privatização do poder, remetendo justamente para o impedimento da encarnação de seus princípios num governante, da mesma forma que os enunciados literários e políticos ${ }^{(30)}$. A caracterização da democracia como o movimento que deslocaria sem cessar os limites do público e do privado corresponderia às necessidades estético-políticas de uma historiografia cujas próprias estruturas poéticas deveriam estar sintonizadas com formas novas de subjetivação que não impedissem o surgimento do dissenso pelo estabelecimento da unidade de novas comunidades imaginárias:

[...] ou a história se dedica primeiro a consolidar seu reconhecimento «científico» sob o risco de liquidar sua aventura própria fornecendo às sociedades dos vencedores a enciclopédia de sua pré-história. Ou se interessa primeiro pela exploração dos múltiplos caminhos com cruzamentos imprevistos pelos quais podem ser apreendidas as formas da experiência do visível e do dizível que constituem a singularidade da época democrática e permitem também repensar outras épocas. [...] nada ameaça tanto a história quanto sua lassidão em relação ao tempo que a fez ou seu medo diante do que fez a matéria sensível de seu objeto: o tempo, as palavras e a morte ${ }^{(31)}$.

\section{Formas de sacralização do político e representação histórica pós- Revolução Francesa}

Apesar da originalidade do entendimento de Rancière acerca dessas novas demandas poéticas do discurso histórico, caberia perguntar sobre as semelhanças entre as características do que chamaria de «regime estético das artes» e as definições de «democracia moderna» de Claude

(30) Jacques Rancière, La haine de la démocratie, Paris, La Fabrique, 2005, p. 69 ss.

(31) Jacques Rancière, Les noms..., cit., p. 207-208. 
Lefort, autor possivelmente mais preocupado em não projetar aspectos considerados típicos das formas de sociedade pós-Revolução Francesa para épocas anteriores. Isto porque as interrogações de Lefort sobre os modos de instituição do social já colocavam em questão os princípios de interiorização que, conferindo um lugar ao poder, fundamentavam formas determinadas de experiência sensível ${ }^{(32)}$. Nos próprios estudos de Lefort, portanto, estava pressuposta uma estreita relação entre estética e política, já que se tratava também do estabelecimento daquilo que se tornava visível e invisível, das formas de ler e nomear que enraizariam a própria natureza simbólica da existência humana e determinariam uma específica relação entre o político e o religioso ${ }^{(33)}$. Além da vinculação implícita entre estética e política, as elaborações teóricas de Lefort buscavam as especificidades das sociedades constituídas a partir de fins do século XVIII e XIX, nas quais a revolução democrática (expressão de Tocqueville) teria operado a impossibilidade de incorporação do poder, tornando-as irrepresentáveis na figura de uma comunidade e passíveis de questionamentos intermináveis.

A impossibilidade da formulação de um enunciado como fundamento da comunidade política, portanto, apareceria como mais claramente característica das democracias modernas em Lefort, não obstante a proposta de Rancière de uma nova poética da historiografia já guardasse vínculos com sua conceituação da democracia. Talvez mais atento à historicidade, Lefort o compreenderia por relação à crise dos fundamentos teológico-políticos que permitiam a encarnação do poder na figura monárquica, ressaltando a democracia moderna como o único regime em que a representação do poder o atestava como «lugar vazio», não passível de incorporação por aquele que governa. Num regime em que a instituição do social se daria sob a forma de um questionamento interminável, o impedimento da apropriação (e, portanto, da privatização) do poder estaria inscrito nos próprios princípios geradores da igualdade que fundamentavam uma específica configuração da relação entre estética e política.

Seria possível argumentar pela diferença da perspectiva de Rancière devido à colocação dos problemas no plano da poética e não da filosofia política, da qual resguardaria suspeita, mas não se deveria esquecer que

(32) Claude Lefort, Essais sur le politique (XIXe-XXe siècles), Paris, Seuil, 1986; L'invention démocratique, Paris, Fayard, 1994.

(33) Claude Lefort, Essais..., cit., p. 260 ss. 
as teses de Lefort foram também elaboradas numa perspectiva crítica em relação ao campo científico, particularmente no que diz respeito às tendências da ciência e da sociologia políticas de compreender a política como uma entre outras esferas da realidade, sem refletir sobre a própria natureza do político ${ }^{(34)}$. Para Lefort, os novos sentidos alcançados nas democracias modernas por noções como Estado, povo, nação, pátria e humanidade já seriam indicativos da impossibilidade de incorporação do poder e sua não percepção corresponderia à fragilidade da atitude científica: «Desinteressar-se dessas noções ou não se deter na função que podem assumir no processo de legitimação do poder seria adotar o ponto de vista artificialista que nos parece característico da ciência» ${ }^{(35)}$.

Ainda é possível argumentar que as concepções de Rancière seriam singulares por estarem referidas à própria escrita da história ao problematizar sua especificidade poética. Não se deveria esquecer, no entanto, que as análises de Lefort se voltaram igualmente para a historiografia de Michelet ao tratar das novas relações entre o político e o religioso que teriam configurado o lugar específico do poder na democracia moderna ${ }^{(36)}$. Em última instância, trata-se novamente da vinculação entre certo imaginário político como forma de representação do poder e a escrita da história, tendo em vista que a recusa de Michelet do fundamento teológico-político identificado como forma de encarnação do poder no Antigo Regime não impediu sua permanência em novos moldes em seus próprios escritos, indicando, inclusive, a fragilidade da oposição que ele mesmo havia estabelecido entre o cristianismo e a Revolução Francesa.

A permanência de formas de religiosidade que vigoravam sob o Antigo Regime não impediria Lefort de ressaltar aspectos novos na escrita histórica de Michelet, na qual a figuração do povo e outras entidades como a pátria, a nação e a humanidade era vista como indicativa da impossibilidade de incorporação do poder característica das formas de instituição do social da revolução democrática. Lefort buscaria uma leitura mais matizada ao destacar a enorme sensibilidade da análise de Michelet sobre o «mistério da encarnação da monarquia», capaz de evidenciar, até mesmo, os limites da aplicação empírica do modelo de Ernst Kantorowicz

(34) Claude Lefort, Essais..., cit.

(35) Claude Lefort, Essais..., cit., p. 270.

(36) Claude Lefort, Essais..., cit., p. 251-300. 
sobre os dois corpos do rei, por reconstituir todo um «registro eróticopolítico» de identificação dos súditos com o monarca. Esse registro, em Michelet, obedeceria não apenas à retomada dos termos jurídicos ou teológico-jurídicos das teorias medievais sobre o duplo corpo de Cristo, mas o conjugaria com a percepção da humanidade do soberano, do caráter sexuado de seu corpo como «corpo amoroso», «corpo falível», que efetuaria uma «mediação inconsciente entre o divino e o humano» ${ }^{(37)}$. A descrição de Michelet do julgamento de Luís XVI, seu sofrimento, sua aparição como um qualquer, apanhado na insignificância do cotidiano, ao mesmo tempo em que indicava um modo específico de sua reintrodução na figura do monarca, seria também o principal exemplo dessa capacidade de Michelet de ser «um dos raros pensadores de seu tempo a reconhecer a função simbólica do poder na mise en forme das relações sociais»(38).

Assim como no caso de Rancière, a interpretação de Lefort formulava uma crítica, mesmo que implícita, a concepções como a de François Furet sobre a Revolução Francesa, indicando que não se deveria opor a escrita histórica de Michelet, tomada como ideológica, a uma história conceitual, presente na obra de Tocqueville ${ }^{(39)}$. Colocado na esteira de uma tradição que, remontando a Michelet, seria denominada de forma genérica como «nova história», Furet foi também um dos principais alvos da crítica de Rancière às conformações poéticas de uma historiografia supostamente conservadora, que emudecia o excesso de palavras característico da época democrática, falando em nome dos sujeitos do passado e, portanto, os silenciando (os mortos). Não se poderia deixar de questionar, entretanto, se a tentativa de Rancière de relativizar o olhar que busca no passado as condições de possibilidade dos acontecimentos, retirando qualquer imprevisibilidade do esforço poético de interpretação, quando levada ao extremo, não tenderia justamente a negligenciar as condições de incerteza vivenciadas pelos sujeitos históricos, principalmente quando confrontados com eventos extraordinários como os da Revolução Francesa.

Desse ponto de vista, a análise de Michelet não pareceria, em pontos determinados, até mais atenta do que a de Rancière à imprevisibilidade dos eventos revolucionários? Fortemente crítica das interpretações

(37) Claude Lefort, Essais..., cit., p. 287.

(38) Claude Lefort, Essais..., cit., p. 284.

(39) Claude Lefort, Essais..., cit., p. 284; François Furet, Pensando a Revolução Francesa, Rio de Janeiro, Paz e Terra, 1989, p. 28; Jacques Rancière, Les noms..., cit., p. 79 ss. 
centradas nas intenções dos agentes, assim como Furet, Mona Ozouf analisou as festas revolucionárias também exploradas por Michelet e não deixou de reconhecer que o historiador francês teria sido o único a perceber a relação entre aquelas festividades e o sentimento de angústia ${ }^{(40)}$. Dialogando com a antropologia e a psicanálise, Ozouf analisou as festas com o objetivo de reconstruir o sentido de imprevisibilidade vivenciado pelos próprios sujeitos da experiência passada, ressaltando não o controle da história pela formulação de narrativas explícitas ou as projeções de futuro conscientes de seus organizadores, mas os desejos de controle da imponderabilidade dos acontecimentos que se expressavam, por exemplo, na repetição do ritual, na valorização do discurso em relação às representações cênicas e na elaboração de um cerimonial de juramento de ódio à realeza somente compreensível pelo medo de um retorno à época da monarquia. Assim, todo um vocabulário de conceitos como «ruminação», «neurose» e «histeria» fundamentaria a análise de Ozouf da festa de comemoração do julgamento de Luís XVI, deslocando para o plano do imaginário aquilo que poderia ser explicado pelos projetos políticos dos planejadores das festividades ${ }^{(41)}$.

Caberia perguntar, como Rancière, repercutindo as críticas de Michel de Certeau à história das mentalidades, qual o lugar de fala dessa historiografia que, tratando das condições de possibilidade que reconstituem todo um imaginário, retira qualquer grau de novidade do evento revolucionário. Nesse caso, talvez fosse importante diferenciar a valorização da imprevisibilidade como ponto de partida da interpretação dos acontecimentos passados, que configura uma forma específica de composição poética (ou teórica?) da narrativa histórica, do enfoque nas incertezas experimentadas pelos próprios agentes, sem o qual o anacronismo que é condição da escrita da história poderia assumir colorações impeditivas justamente da busca de uma relação com o outro (o passado) atenta à radicalidade de sua diferença, aspecto tão caro a Michel de Certeau. Torna-se um desafio, portanto, a elaboração de uma escrita histórica não apenas que valorize o «choque perturbador» que torna os eventos do presente imprevisíveis para os homens do passado, mas que o faça considerando as estruturas de sua própria composição

(40) Mona Ozouf, «A Festa Sob a Revolução Francesa», in Jacques Le Goff e Pierre Nora (orgs.), História: novos objetos, Rio de Janeiro, F. Alves, 1976, p. 223.

(41) Ver também Mona Ozouf, La fête révolutionnaire, 1789-1799, Paris, Gallimard, 1976. 
poética (ou teórica) como elementos que permitem formular um olhar atento à imprevisibilidade daquele mesmo passado, sem o que qualquer possibilidade de irrupção do novo se tornaria obscurecida, conformando uma escrita que, sempre em busca apenas das condições de possibilidade da ocorrência dos eventos, correria o risco de apagar seu próprio lugar de fala ${ }^{(42)}$.

\section{Entre uma "poética do saber» e uma "poética da ausência»?}

As comparações entre as obras de Rancière e Lefort permitem perguntar se aquele último não pareceu mais atento às complexas relações entre descontinuidades e permanências, indicando tanto a novidade quanto a presença de antigos fundamentos teológico-políticos na escrita micheletiana sobre a Revolução. As análises de Lefort sobre a presença do religioso nas democracias modernas, entretanto, parecerão bastante amplas se confrontadas com estudos mais atentos às particularidades nacionais. Fernando Catroga, por exemplo, comparou o caso francês com as formas de religiosidade cívica desenvolvidas em vários países ocidentais ${ }^{(43)}$. O historiador português tratou também das complexas relações entre morte política e formas de incorporação do poder em seu estudo sobre o tiranicídio, além de ter produzido reflexões diversas sobre as relações entre a escrita histórica e os ritos de recordação ${ }^{(4)}$. As comparações entre a historiografia e as práticas de natureza tanatológica, sintetizadas na fórmula "poética da ausência», podem ser confrontadas com proveito com aquilo que Jacques Rancière chamou de «poética do saber» ${ }^{(45)}$.

Tratando do tiranicídio na longa duração, desde a apropriação e do teor pejorativo conferido à palavra tirania (de origem oriental) pelo mundo

(42) Michel de Certeau, L'écriture de l'histoire, Paris, Gallimard, 1975.

(43) Fernando Catroga, Nação, mito e rito, Fortaleza, Museu do Ceará, 2005; Entre Deuses e Césares, Coimbra, Almedina, 2006.

(44) Fernando Catroga, «Em nome... A heroicização do tiranicídio», in Fernando A. Machado et al. (orgs.), Caminhos de Cultura em Portugal. Homenagem ao Professor Doutor Norberto Cunha, Ribeirão/Húmus, Universidade do Minho, 2010, p. 125-166. Sobre as relações entre história e cultos dos mortos, conferir O céu da memória, Coimbra, Minerva, 1999; História, memória e historiografia, Coimbra, Quarteto, 2001; Os passos do homem como restolho do tempo, Coimbra, Almedina, 2009. Sobre o tema, Catroga também orientou a tese de Joana Duarte Bernardes, Para além da imaginação histórica: memória, morte, phantasia, Coimbra, 2014.

(45) Sobre uma «poética da ausência», conferir Fernando Catroga, Os passos..., cit., p. 9 ss. 
greco-romano até suas conformações modernas, Catroga analisou a morte de Luís XVI por meio dos novos vínculos estabelecidos entre o político e o religioso ${ }^{(46)}$. A conformação das filosofias da história, a republicanização dos valores res publicanos, entre outros, foram alguns dos elementos que produziram a convergência entre tiranicídio e regicídio, que permitiu a condenação da própria monarquia como instituição. Nessa interpretação, também não se tratava apenas da morte física do rei, mas da tentativa de desconstrução simbólica de uma forma determinada de incorporação do poder, que caracterizou as religiosidades cívicas ligadas ao chamado processo de «secularização». Não cabe analisar este último tema, objeto de vários estudos de Catroga ${ }^{(47)}$, mas apontar os vínculos entre sua atenção às religiões civis secularizadas e suas interpretações da modernidade, que podem ser importantes na retomada das questões indicadas por Rancière.

Em seu Entre Deuses e Césares, Catroga buscou matizar as teses sobre a modernidade que, numa perspectiva cientificista, postularam um paulatino e inexorável declínio do religioso, assim como aquelas que apostaram num regresso de formas anteriores de sacralidade. Ainda que não estivesse mais amparado num discurso cuja crença no julgamento final e na imortalidade da alma permitia invocar deidades (como aquelas presentes tanto na religião civil de Rousseau quanto nas festas da Revolução, com a figura de Robespierre e o culto do Ser Supremo), o Estado, em vários casos nacionais, continuou a colocar em cena uma espécie de religiosidade cívica, que se mesclaria com a ênfase na educação nacional e que, na França, por exemplo, conformou uma cultura republicana com forte teor laico, mas que não deixou de recorrer a formas de sacralização de entidades imanentes da política.

O mais importante é que a indicação da permanência de fundamentos religiosos na cultura republicana não impediu Catroga de ressaltar formas novas de sacralização do político, criticando, inclusive, as leituras que, fundamentadas na noção de invenção das tradições, apostaram numa «antropologia em que a condição humana fica excessivamente reduzida à sua dimensão racional, o que empobrece a compreensão das suas multímodas expressões históricas» ${ }^{(48)}$. Caberia

(46) Fernando Catroga, «Em nome..., cit., p. 125-166.

(47) Para uma síntese, conferir Fernando Catroga, «Secularização e laicidade. Uma perspectiva histórica e conceptual», Revista de História das Ideias, 25 (2004), p. 51-127.

(48) Fernando Catroga, Entre Deuses..., cit., p. 98. 
perguntar se a configuração de uma nova poética da historiografia proposta por Rancière, pela qual a escrita histórica funcionaria como meio de desincorporação das comunidades imaginárias, não esbarraria justamente nessa dimensão existencial (poderíamos dizer, memorial) que a aproxima de outros ritos de recordação com fundamento identitário. Ainda que tomada como meta, tal fundamentação não ultrapassaria suas potencialidades críticas, sobrevalorizando seu componente racional em detrimento da função de atender às demandas ontológicas do homem pela criação de corpos coletivos imaginários que permitam justamente lidar com as inseguranças do tempo, da palavra e da morte ressaltadas pelo próprio Rancière?

A especificidade da proposta de Rancière se relaciona com a descontinuidade estabelecida entre corpos coletivos imaginados e comunidades políticas, pela qual estas últimas pareceriam mais autênticas por serem fruto de um trabalho de subjetivação política visando a desincorporação que permite a crítica de construções culturais de natureza mais espontânea. É o que se pode perceber na sua caracterização da identidade de «combatente social»:

Uma identidade de combatente social não é, assim, a expressão de nenhuma «cultura» de algum grupo ou subgrupo. Ela é a invenção de um nome para a tomada em consideração de alguns atos de fala que afirmam ou recusam uma configuração simbólica das relações entre a ordem dos discursos e a ordem dos estados. [...] O conceito de cultura, seja quando o aplicamos ao conhecimento dos clássicos ou à fabricação dos sapatos, só tem como efeito apagar este movimento de subjetivação que se opera no intervalo entre várias nomeações e sua fragilidade constitutiva: a ausência de corpo no lugar da voz, a ausência de voz no lugar do corpo, a falha ou intervalo nos quais passam sujeitos de história. Ele identifica e localiza o que apenas tem seu ser no desvio dos lugares e das identidades ${ }^{(49)}$.

Essa leitura de Rancière parece um pouco distinta daquela de Fernando Catroga. Nos estudos do historiador português, as continuidades entre as práticas culturais que conferem sentido às coletividades e aquelas de natureza política constituem pressupostos teóricos importantes, que poderiam contradizer a ênfase de Rancière na atividade do «combatente

(49) Jacques Rancière, Les noms..., cit., p. 197. 
social» como caracterizada apenas pela desincorporação do poder. Os estudos de Catroga sobre os ritos tanatológicos e as comemorações cívicas servem para exemplificá-lo, pois manifestam uma preocupação com as supostas raízes metafísicas dos impulsos que impelem o homem a cultuar os mortos, tendo em vista sua natureza como ser construtor de cultura e de memória. A sensibilidade aos fundamentos familiares das práticas simbólicas de exaltação dos «grandes homens» que alcançaram relevância a partir da segunda metade do século XVIII são indicativas nesse sentido ${ }^{(50)}$. Ao analisar o tema, o historiador considerou não apenas que haveria certa continuidade entre o culto familiar dos mortos e o estabelecimento do novo "imaginário do Panteão", mas que a própria sepultura seria um símbolo referido à perpetuação das famílias, permitindo exemplificar a continuidade existente entre as novas práticas de visita aos cemitérios e as comemorações políticas:

Defende-se assim que, mesmo à escala familiar da «visita ao cemitério», é possível surpreender as características que, numa evidente transferência analógica, as comemorações políticas de raiz tanatológica explicitarão de uma maneira ainda mais evidente. A comemoração é herdeira, não só da solenidade da cerimônia pública de elogio e de menção de um nome, como implica a sacralização do evocado, desenrolando-se, em similitude com a sua matriz - $\mathrm{o}$ ato religioso do culto dos mortos -, num rito eficaz para a memória e, principalmente, para o destino dos vivos ${ }^{(51)}$.

Note-se que, num plano mais profundo, não se trata apenas de considerar a continuidade entre práticas coexistentes em termos históricos, mas de uma compreensão dos fundamentos culturais dos mecanismos de enraizamento em formações coletivas por meio de construções simbólicas e imaginárias. Até porque a noção de família remeteria, em última instância, àquela de pátria, tomada em outro texto do autor como uma «espécie de alfa fundador de todas as filiações étnico-culturais e políticas, matriz que age como um apelo, ou melhor, como uma herança, cujo dever de transmissibilidade acena para

(50) Fernando Catroga, «Ritualizações da história», in Fernando Catroga, Luís Reis Torgal e José Amado Mendes, História da História em Portugal, Lisboa, Círculo de Leitores, 1996, p. 547-671.

(51) Fernando Catroga, O céu..., cit., p. 23. 
contornos escatológicos» ${ }^{(52)}$. Presente ainda nos poemas homéricos como forma originária de identificação coletiva, quando resguardava um sentido predominantemente relacionado à população e ao território, a noção de pátria deveria ser diferenciada de outras como patriotismo, nação e nacionalismo justamente considerando o maior ou menor grau de institucionalização e uso político dessas construções imaginadas em relação às demandas afetivas e identitárias do homem pela homogeneização dos sentimentos de pertença ${ }^{(53)}$.

A pressuposição de certa continuidade entre o culto familiar dos mortos e as comemorações políticas de natureza tanatológica deve ser compreendida em sua ligação com a forma relacional e não dicotômica de tratamento de pares conceituais como recordação e comemoração, memória individual e memória coletiva, ou mesmo história e memória. Nesse caso, o afastamento da tendência cientificista presente em determinadas obras de Maurice Halbwachs, propensas a certa reificação da «memória coletiva», não impediu Catroga de entender a recordação como um ato de alteridade, que tomaria de empréstimo formas públicas de produção narrativa de sentido, dialogando com a perspectiva de Paul Ricoeur, para quem a memória do indivíduo deveria ser entendida como um fenômeno relacional e intersubjetivo ${ }^{(54)}$. Daí a importância da linguagem pública do rito, fenômeno que, por sua natureza memorial, guardaria as mesmas características pragmáticas e normativas de outras práticas culturais dissimuladoras da morte, como a própria historiografia, também caracterizada por suas funções existenciais de distinção, filiação e identificação $0^{(55)}$.

Trata-se também, portanto, da valorização de uma tradição sociológica para a qual os ritos, como condicionantes antropológicos fundados na natureza do homem como animal simbólico, possuiriam sempre uma função «instituinte de sociabilidades», sacralizando e sancionando um estado de coisas por meio da naturalização das diferenças, que se tornam duráveis porque reconhecidas. A releitura proposta por Pierre Bourdieu da noção de «rito de passagem», de Arnold van Gennep, acentuando

(52) Fernando Catroga, «Pátria, nação e nacionalismo», in Luís Reis Torgal, Fernando Tavares Pimenta e Julião Soares Sousa (orgs.), Comunidades imaginadas, Coimbra, Universidade de Coimbra, 2008, p. 21.

(53) Fernando Catroga, «Pátria..., cit., p. 20.

(54) Fernando Catroga, O céu..., cit., p. 13-14.

(55) Fernando Catroga, O céu..., cit., p. 24 ss. 
sua dimensão de construção simbólica de uma ordem social, permitiu a Fernando Catroga entender a própria historiografia como prática cultural com uma função de «rito de instituição» ${ }^{(56)}$. Esse tipo de leitura, de fato, parece relevante à compreensão de certas diferenças em relação a Rancière, tendo em vista uma possível maior desconfiança deste último das análises sociológicas e também suas incisivas críticas aos usos da categoria cultura, já que essas duas formas de tratamento histórico guardariam semelhanças por desconsiderarem os fundamentos poéticos das próprias categorias que empregam ${ }^{(57)}$.

Tal fato não impediria a existência de certas semelhanças entre os autores, ou mesmo que Catroga estivesse atento à dimensão crítica que confere especificidade à história como rito de recordação, tendo em vista o «imperativo ético e deontológico» que obriga o historiador a interrogar-se sobre o que ficou esquecido, desenterrando «os 'esqueletos' escondidos nos armários da memória» ${ }^{(58)}$. Talvez se possa perguntar se a ênfase na dimensão poética da historiografia não levou Rancière a subvalorizar sua função existencial como rito de recordação, certamente mais enfocada por Catroga. A crítica de Rancière à ingênua crença de Michelet de que não existiriam vozes sem corpo (já que o esquecimento do caráter linguístico da categoria «povo» permitiria dotar de sentido a História da França), embora procedente, não correria o risco de tornar-se parte do excesso de racionalismo que acompanhou a constituição de novas formas de religiosidade cívica secularizadas? Qual a verdadeira capacidade do discurso histórico de desconstrução das comunidades políticas imaginárias e de promoção de certo ideal de emancipação intelectual?

Sem dúvida, as interrogações de ambos os autores sobre as relações entre a história e a morte remetem para a vocação crítica da historiografia e seu papel na fragilização dos modos diversos de incorporação do poder, permitindo, apesar dos diferentes enfoques, colocar em questão as próprias formas da representação histórica. Estaria a historiografia condicionada por uma complexa relação entre uma "poética da ausência» e uma «poética do saber»? Talvez reflexões sobre a memória, a morte e o poder possam ajudar a pensá-lo, abrindo caminho para uma reflexão sobre o lugar da

(56) Fernando Catroga, Os passos..., cit., p. 15. Pierre Bourdieu, Langage et pouvoir symbolique, Paris, Seuil, 2001, p. 175-186.

(57) Jacques Rancière, Les noms..., cit., p. 198 ss.

(58) Fernando Catroga, «Memória e História», in Sandra Pesavento, Fronteiras do Milênio, Porto Alegre, UFRGS, 2001, p. 67. 
teoria na escrita da história e permitindo elaborar respostas que, jamais sendo tomadas com as únicas possíveis (afinal, são históricas), poderiam ser conduzidas a partir do diálogo entre diversos campos disciplinares. Afinal, o que significaria o estabelecimento de fronteiras muitos restritas entre os campos de saber se não uma tentativa de imposição de limites e, portanto, de evitar nada mais do que a própria morte? 